\title{
Communication
}

\section{Flexural property of composite biomaterials used in the oral cavity}

\author{
Masao Irie ${ }^{1 *}$, Yukinori Maruo ${ }^{2}$, Goro Nishigawa ${ }^{3}$ and Takuya Matsumoto ${ }^{4}$ \\ 1 Department of Biomaterials, Okayama University Graduate School of Medicine, Dentistry and \\ Pharmaceutical Science; mirie@md.okayama-u.ac.jp \\ 2 Department of Occlusion and Removable Prosthodontics, Okayama University; ykmar@md.okayama- \\ u.ac.jp \\ 3 Department of Occlusion and Removable Prosthodontics, Okayama University; goro@md.okayama-u.ac.jp \\ 4 Department of Biomaterials, Okayama University Graduate School of Medicine, Dentistry and \\ Pharmaceutical Science; tmatsu@md.okayama-u.ac.jp
}

* Correspondence: mirie@md.okayama-u.ac.jp; Tel.: +81-86-235-6668 (I.M.)

\begin{abstract}
Composite materials are widely used in the dental field in clinics as biomaterials. For example, it has been used as a biomaterial to repair caries and restore masticatory function, and as a cement to adhere the restoration to the tooth substrate. In order to demonstrate its function, dental biomaterials are measured their mechanical strength. From such basic research, we explained the potential of dental biomaterials, especially flexural strength and modulus of elasticity. Mechanical properties of dental biomaterials similar to those of the tooth, thermal stimulation, and aesthetic elements in the oral cavity. In this part, we will introduce the commercialized products of composites suitable for the characteristics and tooth quality, and provide the reader with the characteristics from the flexural characteristics of the composite materials used in clinical dentistry. In clinical performance, it might be advisable to delay polishing when composite biomaterials are used for luting materials, filling materials and core build-up materials since improved the flexural strength and the flexural modulus of elasticity were displayed after 1-day storage. And it is thought that flexural strength or characteristics is a significant important mechanical property of oral biomaterials.
\end{abstract}

That is, this communication was constructed based on three papers: 1) Dent. Mater. 2010, 26, 608-615., 2) PLOS ONE, 2017, 12: e0183381., 3) Polymers, 2020, 12, 2947, regarding the flexural characteristics of composite materials.

Keywords: Biomaterial, Dental composite, Luting agents, Core build-up materials, Application in dentistry

\section{INTRODUCTION}

Composite materials are widely used in the dental field in clinics as biomaterials. For example, it has been used as a biomaterial to repair caries and restore masticatory function, and as a cement to adhere the restoration to the tooth substrate. In order to demonstrate its function, dental biomaterials are measured by measuring their own flexural strength and flexural modulus of elasticity using luting materials, filling materials and core build-up materials. As mentioned above, composite is used with various restoration materials in dental clinics, but all have the same composition, namely, composites consist of three phases: resin matrix, dispersed inorganic filler particles, and silane coupling agent on the filler particles to produce a good bond between the matrix and the filler in the clinical dentistry. 
The mechanical properties of restorative filling materials and luting agents have been evaluated using in vitro flexural testing [1-11]. In our previous studies [4, 9, 11], dental restorations which were polished after one-day storage following light activation showed improved shear bond strength and flexural properties, and thus improved marginal integrity. For luting agents, their shear bond strengths to dentin and flexural moduli increased after one-day storage, coupled with markedly decreased incidence of interfacial gaps [7].

Therefore, it will be introduced an example in which the general composite material, which is the theme of this subject, is used in the clinical practice of dentistry because of the flexural characteristics of the "composite material" actually used in the clinical practice of dentistry, that is, the restorative material.

\section{Luting Materials [7].}

\section{1-1. Introduction.}

In clinical practice, the popularity of tooth-colored posterior restorations has increased due to demand for esthetic restoratives and also a growing concern about the biocompatibility of amalgam. Resin composite showed better performance than luting-agents for indirect esthetic restorations. Luting-agents for composite inlay restorations are produced in dual-polymerized formulations, which are indicated for restorations with material opacity sufficient to inhibit light energy from transmission to the cement. Although light irradiance reaching the cement may often initiate the surface polymerization process, a self-cure chemical agent and some time is needed to ensure a maximal cure [3,4]. These systems embody dual-setting processes consisting of photo-polymerization and an acid-base reaction. The final set material has glass particles sheathed in a matrix consisting of two networks, one derived from the resin.

This investigation was, therefore, carried out with multiple types of dual-cured luting-agents to evaluate early stage behavior (both immediate and after 1-day storage).

\section{1-2. Materials, Methods and Results.}

\section{1-2-1. Materials.}

The sources, compositional details and classification of the seven luting-agents used in this study, together with their pretreatment agents, are summarized in Tables 1. All procedures were performed in accordance with the manufacturers' instructions. Capsules of RelyX Unicem Aplicap were triturated using a high-speed mixer (Silamat, Vivadent, Schaan, Liechtenstein) for $15 \mathrm{~s}$. For light activation, a curing unit (New Light VL-II, GC, Tokyo, Japan; optic diameter: $8 \mathrm{~mm}$ ) was used. The light irradiance was checked immediately before each application to the materials, using a radiometer (Demetron/Kerr, Danbury, CT, USA). During the experiment the light irradiance was maintained at $450 \mathrm{~mW} / \mathrm{cm}^{2}$.

Table 1. Luting-agents investigated. Information provided by the manufacturers.

\begin{tabular}{|c|c|c|}
\hline Materials & Manufacturer & Material composition \\
\hline \multicolumn{3}{|c|}{ Self-adhesive Resin Cement } \\
\hline RelyX Unicem & 3M ESPE, Seefeld & Filler content 72 wt\% (aluminosilicate, Silanized filler) \\
\hline Aplicap & Germany & Methacrylates, Initiators, Acidic Methacrylates \\
\hline \multicolumn{3}{|c|}{ Adhesive Resin Cement } \\
\hline Calibra & $\begin{array}{l}\text { Dentsply/Caulk } \\
\text { Milford, DE, USA }\end{array}$ & $\begin{array}{l}\text { Filler content } 67-68 \text { wt } \% \text { (Silica fume) Bis-GMA, } \\
\text { TEGDMA, Titanium Dioxide, catalyst }\end{array}$ \\
\hline NEXUS 2 & $\begin{array}{l}\text { Kerr, Orange CA, } \\
\text { USA }\end{array}$ & $\begin{array}{l}\text { Filler content } 70 \mathrm{wt} \% \text { (fumed silica and barium } \\
\text { aluminosilicate) Bis-GMA, TEGDMA, EBPADMA, } \\
\text { HEMA, UDMA, catalyst }\end{array}$ \\
\hline Panavia F & $\begin{array}{l}\text { Kuraray medical, } \\
\text { Kurashiki, Japan }\end{array}$ & $\begin{array}{l}\text { Filler content } 78 \text { wt } \% \text { Paste A: MDP, Comonomer, } \\
\text { Filler, NaF, BPO } \\
\text { Paste B: Comonomer, Filler, NaF, amine, initiator }\end{array}$ \\
\hline LINK MAX & GC, Tokyo Japan & $\begin{array}{l}\text { Filler content } 68 \text { wt } \% \text { (fluoroalumonisilicate glass, } \mathrm{SiO} \text { ) } \\
\text { UDMA, HEMA, dimethacrylate, catalyst }\end{array}$ \\
\hline
\end{tabular}




\begin{tabular}{lll} 
Bistite II & Tokuyama Dental & Filler content 77wt\% (Silica-Zirconia) MAC-10, \\
& Tokyo, Japan & EBPADMA, Monomer, initiator \\
Chemiace II & P: Complexed filler, SiO2, ZrO2, Amine \\
& Moriyama, Japan & L: 4-META, HEMA, Dimethacrylate, BPO, Powder/Liquid: \\
& 1.15 \\
\hline Bis-GMA: bisphenol A glycidylmethacrylate, BPO: benzoyl peroxide, EBPADMA: ethoxylated bisphenol A, \\
dimethacrylate, HEMA: 2- hydroxyethyl methacrylate, MAC-10: 11-methacryloxy-1,1-undecanedicarboxylic acid, \\
4-META: 4-methacryloxyethyl trimellitate anhydride, MMA: methyl methacrylate, TEGDMA: tri-ethylene-glycol- \\
dimethacrylate, UDMA, urethan dimethacrylate
\end{tabular}

1-2-2. Methods and Results.

Teflon molds $(25 \times 2 \times 2 \mathrm{~mm})$ were used to prepare flexural specimens ( $\mathrm{n}=10$ /group). Bistite II, Chemiace II, Compolute and XenoCem were cured in three overlapping sections, each cured for 30 s. Flexural strength and flexural moduli of elasticity were measured, both immediately after setting and after 1-day storage, using the three-point bending method with a $20 \mathrm{~mm}$-span and a load speed of $0.5 \mathrm{~mm} / \mathrm{min}$ (5565, Instron, Canton, MA, USA) as outlined in ISO 9917-2 (1996) and were calculated (Software Series IX, Instron, Canton, MA, USA).

Table 2 and 3 summarize the flexural strength and flexural modulus at the two time-points, respectively. In the immediate condition, Bistite II showed the greatest flexural modulus of all materials and Chemiace II showed the lowest value. After 1-day, the moduli of all luting-agents significantly increased. Panavia F and Bistite II showed the greatest moduli of all materials.

\section{1-2-3. Discussions.}

Thus the higher value of flexural strength and flexural modulus after 1-day, compared with the immediate condition, resulted partly from the stiffer luting-agents with higher moduli $[4,9,11]$, The improvement in strength and elastic modulus after one day is a result of the improvement in the polymerization rate of cement over time [11].

Table 2. Flexural strength of luting-agents (MPa, mean (S.D.))

\begin{tabular}{lccc}
\hline Luting agent & Immediately & After 1-day storage & $\boldsymbol{p}$ value $^{*}$ \\
\hline RelyX Unicem Aplicap & $64.9(6.7)$ & $88.8(4.4)$ & $<0.001$ \\
Calibra & $73.7(7.4)$ & $120.1(11.7)$ & $<0.001$ \\
NEXUS 2 & $83.4(8.1)$ & $123.0(9.2)$ & $<0.001$ \\
Panavia F & $34.8(5.6)$ & $99.8(10.6)$ & $<0.001$ \\
LINK MAX & $107.8(10.6)$ & $159.4(19.5)$ & $<0.001$ \\
Bistite II & $73.2(9.4)$ & $108.1(14.7)$ & $<0.001$ \\
Chemiace II & $37.1(3.9)$ & $57.8(3.7) \mathrm{j}$ & $<0.001$ \\
\hline$n=10 . \quad *$. -Test. & & &
\end{tabular}

Table 3. Flexural modulus of luting-agents (GPa, mean (S.D.))

\begin{tabular}{lccc}
\hline Luting agent & Immediately & After 1-day storage & $p$ value* \\
\hline RelyX Unicem & $4.57(0.55)$ & $7.86(0.81)$ & $<0.001$ \\
Calibra & $1.88(0.20)$ & $6.47(0.30)$ & $<0.001$ \\
NEXUS 2 & $3.10(0.41)$ & $6.69(0.35)$ & $<0.001$ \\
Panavia F & $2.75(0.25)$ & $9.65(1.01)$ & $<0.001$ \\
LINK MAX & $3.33(0.82)$ & $7.51(0.49)$ & $<0.001$ \\
Bistite II & $5.23(0.41)$ & $9.61(1.11)$ & $<0.001$ \\
Chemiace II & $0.47(0.14) \mathrm{e}$ & $3.39(0.26) \mathrm{j}$ & $<0.001$ \\
\hline$n=10 . \quad *$-Test. & & &
\end{tabular}

\section{Filling Materials [9].}

\section{2-1. Introduction.}

Polymerization shrinkage occurs during the early stage of polymerization of light-activated dental composites. This phenomenon adversely affects interfacial adaptation and bonding to tooth 
structure because the shrinkage forces generated can disrupt the bond to cavity walls and result in gap formation. As for the adhesive systems used to bond the restorative filling materials to tooth structure, their issues of flow ability, polymerization shrinkage and the resulting destructive shrinkage stress further contribute to gap formation in resin composite restorations. Compromised marginal integrity at the resin-tooth interface will lead to bacterial penetration, and subsequently pulpal damage and postoperative sensitivities. One way to predict the clinical success of dental composite restorations in vitro is to evaluate marginal adaptation. In butt-joint cavities restored with an adhesive system and a resin composite filling, the magnitude of interfacial gaps formed is dictated by these factors: (1) adhesive forces between the restorative material and cavity walls; (2) degrees of volumetric contraction of filling and luting materials; and (3) flow properties of filling and luting materials. Self-etch primer adhesive systems and all-in-one adhesives vary in their acidity because of differences in the composition and concentration of polymerizable acids and/or acidic resin monomers [4, 7-15].

This investigation was carried out with filling materials to evaluate early stage behavior (both immediate and after 1-day storage).

\section{2-2. Materials and methods.}

\section{2-2-1. Materials and Methods.}

Nine light-activated resin composite filling materials for premolar restorations were selected for this study. Details of these resin composite filling materials are listed in Table 4.

These resin composite restorative materials and adhesives systems were selected because they were the major restorative products used by dentists and thus provided a comprehensive, clinically relevant range of values for the parameters to be investigated in this study.

The method is the same as 1-2-2.

Table 4. Light-activated restorative materials investigated

\begin{tabular}{|c|c|c|c|}
\hline Product & Composition & Manufacturer & Lot No. \\
\hline QuiXX & $\begin{array}{l}\text { Silica nanofiller (86 wt } \%, 66 \text { vol\%) Bis-EMA, UDMA, } \\
\text { TEGDMA, TMPTMA, Photo initiators, Stabilisers }\end{array}$ & $\begin{array}{l}\text { Dentsply/Caulk } \\
\text { Milford, DE, USA }\end{array}$ & 0503000635 \\
\hline Filtek P60 & $\begin{array}{l}\text { Zirconia/silica ( } 83 \mathrm{wt} \%, 61 \text { vol\%) Bis-GMA, UDMA, Bis-EMA, } \\
\text { Photo initiators stabilizers }\end{array}$ & $\begin{array}{l}\text { 3M ESPE, St. Paul, } \\
\text { MN, USA }\end{array}$ & $3 \mathrm{TC}$ \\
\hline $\begin{array}{l}\text { Herculite } \\
\text { XRV }\end{array}$ & $\begin{array}{l}\text { Barium silica glass (79 wt \%, } 59 \text { vol } \% \text { ) Bis-GMA, TEGDMA, } \\
\text { EBPADMA }\end{array}$ & $\begin{array}{l}\text { Kerr, Orange, CA, } \\
\text { USA }\end{array}$ & 112330 \\
\hline $\begin{array}{l}\text { Tetric N- } \\
\text { Ceram }\end{array}$ & $\begin{array}{l}\text { Bariumglass filler, Ytterbiumtrifluoride, Mixed oxide }(63.5 \\
\text { wt } \%, 55-57 \text { vol } \%) \text {, Prepolymer (17\%) UDMA, Bis-EMA, Bis- } \\
\text { GMA, Photo initiators }\end{array}$ & $\begin{array}{l}\text { Ivoclar Vivadent AG, } \\
\text { Schaan, Liechtenstein }\end{array}$ & KO4764 \\
\hline $\begin{array}{l}\text { Gradia } \\
\text { Direct P }\end{array}$ & $\begin{array}{l}\text { Silica powder, Prepolymerized filler Fluoro-aluminosilicate- } \\
\text { glass ( } 79 \mathrm{wt} \%, 65 \mathrm{vol} \% \text { ) UDMA, Dimethacrylate, Pigment, } \\
\text { Photo initiators }\end{array}$ & GC, Tokyo, Japan & 0403301 \\
\hline $\begin{array}{l}\text { BEAUTIFIL } \\
\text { II }\end{array}$ & $\begin{array}{l}\text { S-PRG filler, multi-functional glass filler Ultra-fine filler (83.3 } \\
\text { wt } \%, 68.6 \text { vol\%) Bis-GMA, TEGDMA, UDA, Photo initiators }\end{array}$ & Shofu, Kyoto, Japan & 110615 \\
\hline EPIC-AP & $\begin{array}{l}\text { Barium glass filler, TMPT reactive filler ( } 82 \mathrm{wt} \%, 64 \mathrm{vol} \% \text { ) } \\
\text { Dimethacrylates, Photoinitiator, Stabilizer }\end{array}$ & $\begin{array}{l}\text { Sun Medical } \\
\text { Moriyama, Japan }\end{array}$ & $\mathrm{MX} 2 \mathrm{~F}$ \\
\hline $\begin{array}{l}\text { Estelite } \\
\text { Sigma }\end{array}$ & $\begin{array}{l}\text { Silica/zirconia filler ( } 82 \mathrm{wt} \%, 71 \mathrm{vol} \% \text { ) Bis-GMA, TEGDMA, } \\
\text { Bis-MPEPP, Photo initiators }\end{array}$ & $\begin{array}{l}\text { Tokuyama Dental } \\
\text { Tokyo, Japan }\end{array}$ & $011 K 2$ \\
\hline $\begin{array}{l}\text { Clearfil AP- } \\
\text { X }\end{array}$ & $\begin{array}{l}\text { Silanater glass ceramics, Surface treated alumina micro } \\
\text { filler( } 85.5 \mathrm{wt} \%, 71.0 \mathrm{vol} \%) \text { Bis-DGMA, TEGDMA, } \\
\text { Hydrophobic aromatic dimetnacrulate, dl-Camphorquinone }\end{array}$ & $\begin{array}{l}\text { Kuraray Medical } \\
\text { Kurashiki, Japan }\end{array}$ & $1121 \mathrm{AA}$ \\
\hline \multicolumn{4}{|c|}{$\begin{array}{l}\text { Bis-EMA: Bisphenol A ethoxyl methacrylate, UDMA: Urethane dimethacrylate, TEGDMA: Tri-ethylene-glycol } \\
\text { dimethacrylate, TMPTMA: Trimethylolpropane trimetharylate, Bis-GMA: Bisphenol A glycidyl methacrylate, Bis- } \\
\text { DGMA: Bisphenol A diglycidyl mentacrylate, TMPT: Trimethylolpropane trimetharylate, EBPADMA: Ethoxylated } \\
\text { bis-phenol-A-dimethacrylate, UDA: Urethane diacrylate, S-PRG: Surface reaction type pre-reacted glass-ionomer } \\
\text { filler, Bis-MPEPP: 2,2-Bis(4-methacryloyloxypolyethoxyphenyl)propane }\end{array}$} \\
\hline
\end{tabular}

\section{2-2-2. Results.}


Tables 5 and 6 present the flexural strength and modulus data, respectively, obtained at two time points.

Significant differences $(p<0.05)$ in flexural strength were observed between the immediate time point and after 1-day storage for all resin composite filling materials, ranging from $+31 \%$ to $+80 \%$. Immediately after setting, Clearfil AP-X showed the highest value while Gradia Direct P showed the lowest. After 1-day storage, P-60 and Clearfil AP-X showed the highest values, while Gradia Direct $\mathrm{P}$ and Estelite Sigma showed the lowest.

For flexural modulus data, significant differences $(p<0.05)$ were observed between the immediate time point and after 1-day storage for all restorative materials, ranging from $+62 \%$ to $+149 \%$. Immediately after setting, Clearfil AP-X showed the highest value while Gradia Direct P and Estelite Sigma showed the lowest. After 1-day storage, QuiXX and Clearfil AP-X showed the highest values, while Gradia Direct P showed the lowest.

\section{2-2-3. Discussions.}

Thus the higher value of flexural strength and flexural modulus after 1-day, compared with the immediate condition, resulted partly from the stiffer luting-agents with higher moduli $[4,9,11]$, The improvement in strength and elastic modulus after one day is a result of the improvement in the polymerization rate of cement over time [11].

In this study, commercially available resin composites were used for investigation. Despite significant differences in bonding performance, all composites displayed similar tendencies in their bond strengths to enamel and dentin and in their flexural properties when measured immediately after polishing and after 1-day storage. This could be attributed to their similar filler-matrix ratios [18].

Greater interfacial integrity exhibited by resin composite restorations in this study could stem from a combination of factors: smaller polymerization shrinkage, lower polymerization shrinkage stress, and good bond strength. In clinical settings, it might be advisable to delay polishing when resin composites are used for Class I restorations since improved mechanical properties were displayed after one-day storage. The clinical implication is that dentists and patients must agree to a next-day return visit for polishing to improve the survival rate of their restorations.

Table 5. Flexural strength of restorative materials (MPa, mean (S.D.))

\begin{tabular}{lcccc}
\hline Restoration & Immediately & After one-day storage & Change (\%) ${ }^{*}$ & $p$ value a \\
\hline QuiXX & $84.4(3.3)$ & $143.8(12.1)$ & +70 & $<0.05$ \\
P-60 & $102.0(5.6)$ & $165.1(9.8)$ & +62 & $<0.05$ \\
Herculite XRV & $75.5(9.3)$ & $135.9(10.5)$ & +80 & $<0.05$ \\
Tetric EvoCeram & $84.1(5.0)$ & $122.7(3.5)$ & +46 & $<0.05$ \\
Gradia Direct P & $52.2(3.5)$ & $91.5(7.0)$ & +75 & $<0.05$ \\
BEAUTIFIL II & $77.0(4.9)$ & $113.9(11.3)$ & +48 & $<0.05$ \\
EPIC AP & $62.2(5.0)$ & $108.6(10.4)$ & +75 & $<0.05$ \\
Estelite Sigma & $61.9(5.4)$ & $93.5(7.1)$ & +51 & $<0.05$ \\
Clearfil AP-X & $128.4(7.6)$ & $167.9(14.1)$ & +31 & $<0.05$ \\
\hline
\end{tabular}

$n=10$, \#: Percentage to the immediate condition, a: $t$-Test.

Table 6. Flexural modulus of restorative materials (GPa, mean (S.D.))

\begin{tabular}{lcccc}
\hline Restoration & Immediately & After one-day storage & Change (\%) ${ }^{*}$ & p value a \\
\hline QuiXX & $9.29(2.63)$ & $18.21(1.71)$ & +96 & $<0.05$ \\
P-60 & $8.62(1.24)$ & $15.76(1.19)$ & +83 & $<0.05$ \\
Herculite XRV & $4.77(0.13)$ & $11.88(0.70)$ & +149 & $<0.05$ \\
Tetric EvoCeram & $6.04(0.87)$ & $9.21(0.88)$ & +52 & $<0.05$ \\
Gradia Direct P & $2.78(0.22)$ & $5.26(0.31)$ & +89 & $<0.05$ \\
BEAUTIFIL II & $7.05(0.86)$ & $11.78(0.99)$ & +67 & $<0.05$ \\
EPIC AP & $5.26(0.50)$ & $10.77(0.73)$ & +105 & $<0.05$ \\
Estelite Sigma & $3.59(0.19)$ & $6.88(0.46)$ & +92 & $<0.05$ \\
Clearfil AP-X & $10.99(0.98)$ & $17.76(1.35)$ & +62 & $<0.05$ \\
\hline
\end{tabular}

$n=10$, \#: Percentage to the immediate condition, a: $t$-Test. 


\section{Core Build-up Materials [11].}

\section{3-1. Introduction.}

An endodontically treated tooth presents a higher risk of biomechanical failure than a vital tooth. An appropriate restoration for endodontically treated teeth is guided by both strength and esthetics. Posts are generally used to restore missing tooth structure and pulpless teeth, and new tooth-colored posts have improved the esthetics of teeth restored with posts and cores. To ensure the durability of endodontically treated teeth, it is extremely important that posts are optimally bonded to reduce debonding and fracture risks.

A core build-up system usually comprises a post, and it restores the tooth to the extent necessary to support a crown or an abutment tooth. Therefore, a core build-up material, such as resin composite, is a restoration placed in a badly broken-down tooth to restore the bulk of the tooth's coronal portion. Various types of bonding systems have been used with different luting cements and core build-up materials. Improvements in resin composites and advances in tooth substrate bonding systems have enabled the employment of more conservative techniques, which seek to maximally preserve the vitality of badly broken-down permanent premolar or molar teeth in their restoration. To provide post retention and improve the overall resistance of the root against fracture, resin composite core build-up materials are now widely used with an adhesive system [19-21].

This investigation was, therefore, carried out with multiple types of core build-up dual-cured materials to evaluate early stage behavior (both immediate and after 1-day storage).

\section{3-2. Materials, Methods and Results.}

\section{3-2-1. Materials and Methods.}

The manufacturers and compositional details of eight core build-up materials and three luting materials in Tables 7. All procedures were performed in accordance with the manufacturers' instructions. For light activation, a light curing unit (New Light VL-II, GC, Tokyo, Japan; optic diameter: $8 \mathrm{~mm}$ ) was used. Before each application to the materials, light irradiance was checked using a radiometer (Demetron Kerr, Danbury, CT, USA). During the experiment, light irradiance was maintained at $450 \mathrm{~mW} / \mathrm{cm}^{2}$. The method is the same as 1-2-2.

Since there are many build-up materials this time, we focused on flexural strength.

Table 7. Core materials investigated

\begin{tabular}{|c|c|c|c|}
\hline Product & Composition & Manufacturer & Batch No. \\
\hline FluoroCore 2+ & $\begin{array}{l}\text { Barium fluoro alumino borosilicate glass (Silanated), } \\
\text { Sialne treated silica, Aluminum Oxide, Bis-GMA, } \\
\text { Urethane Dimetacrylate, Polymerizable dimetacrylate, } \\
\text { Benzoyl Peroxide, Filler content: } 69.1 \mathrm{wt} \text { \%, } 46 \text { vol. \%. } \\
\text { The particle size ranges from } 0.04 \text { to } 25 \mu \mathrm{m} .\end{array}$ & $\begin{array}{l}\text { Dentsply/Caulk, } \\
\text { Milford, DE, } \\
\text { USA }\end{array}$ & 160415 \\
\hline RelyX Ultimate & $\begin{array}{l}\text { Surface treated Glass Powder Filler, Phosphate ester } \\
\text { monomer, TEGDMA, 1,12-Dodecane Dimethaycrylate, } \\
\text { silica Filler, Initiator, Calcium Hydroxide, Titanium } \\
\text { Dioxide, Filler content: about } 70 \text { wt. \% }\end{array}$ & $\begin{array}{l}\text { 3M, Seefeld, } \\
\text { Germany }\end{array}$ & 642680 \\
\hline RelyX Unicem 2 Automix & $\begin{array}{l}\text { Surface treated Glass Powder Filler, Phosphate ester } \\
\text { monomer, TEGDMA, 1,12-Dodecane Dimethaycrylate, } \\
\text { Silica Filler, Initiator, Calcium Hydroxide, Sodium p- } \\
\text { Toluensulfinatet, Methacrylated Amine, Titanium } \\
\text { Dioxide, Filler content: about } 70 \text { wt. \% }\end{array}$ & $\begin{array}{l}\text { 3M, Seefeld, } \\
\text { Germany }\end{array}$ & 646984 \\
\hline $\begin{array}{l}\text { Filtek Bulkfill Flowable } \\
\text { Restorative }\end{array}$ & $\begin{array}{l}\text { Silane Treated Ceramic, UDMA, Bis EMA, Bis-GMA, } \\
\text { TEGDMA, Other Dimethacrylate, Ytterbium Fluoride, } \\
\text { Filler content: } 64.5 \mathrm{wt} \% \text {, } 42.5 \mathrm{vol} \%\end{array}$ & $\begin{array}{l}\text { 3M, St. Paul, } \\
\text { USA }\end{array}$ & N815551 \\
\hline NX3 & $\begin{array}{l}\text { Barium Aluminoborosilicate glass, Ytterbium } \\
\text { trifluoride, Fumed Silica, TEGDMA, UDMA, } \\
\text { EBPADMA, Initiator, Stabilizer, Filler content: } 67.5 \\
\text { wt. } \%, 43.3 \text { vol. } \%\end{array}$ & $\begin{array}{l}\text { Kerr, Orange, } \\
\text { CA, USA }\end{array}$ & 6021181 \\
\hline
\end{tabular}




\begin{tabular}{|c|c|c|c|}
\hline MultiCore Flow & $\begin{array}{l}\text { Ytterbium trifluoride, Bis-GMA, UDMA, TEGDMA, } \\
\text { Dibenzoyl peroxide, Filler content: } 70 \mathrm{wt} \text {. } \%, 46 \text { vol. } \% \text {, } \\
\text { The particle size ranges from } 0.04 \text { to } 25 \mu \mathrm{m} \text {. }\end{array}$ & $\begin{array}{l}\text { Ivoclar } \\
\text { Vivadent AG, } \\
\text { Schaan, } \\
\text { Liechtenstein }\end{array}$ & W02582 \\
\hline UniFil Core EM & $\begin{array}{l}\text { UDMA, Dimethacrylate, Fluoroaluminosilicate glass, } \\
\text { Iron oxide, Dibenzoyl peroxide, Butylated } \\
\text { hydroxytoluene, Filler content: } 75 \text { wt. } \%\end{array}$ & $\begin{array}{l}\text { GC, Tokyo, } \\
\text { Japan }\end{array}$ & 1604251 \\
\hline Beauti Core Flow Paste & $\begin{array}{l}\text { Glass Powder Filler (S-PRG Filler), Bis-GMA, } \\
\text { TEGDMA, Silica, Initiator, Others, Filler content: 60-70 } \\
\text { wt. } \%\end{array}$ & $\begin{array}{l}\text { Shofu, Kyoro, } \\
\text { Japan }\end{array}$ & 61610 \\
\hline i-TFC system Post Resin & $\begin{array}{l}\text { Dimethacrylates, Silica, Barium glass filler, } \\
\text { Photoinitiators, Stabilizer, Others Filler content: } 67 \text { wt. } \%\end{array}$ & $\begin{array}{l}\text { Sun Medical, } \\
\text { Moriyama, } \\
\text { Shiga, Japan }\end{array}$ & MX13 \\
\hline ESTECORE & $\begin{array}{l}\text { Bis-GMA, TEGDMA, Bis-MPEPP, Silica-Zirconia Filler, } \\
\text { Camphorquinone, Peroxide, Radial amplifier, Others, } \\
\text { Filler content: } 75 \text { wt. } \%\end{array}$ & $\begin{array}{l}\text { Tokuyama } \\
\text { Dental, Tokyo, } \\
\text { Japan }\end{array}$ & 112006 \\
\hline $\begin{array}{l}\text { Clearfil DC Core Automix } \\
\text { ONE }\end{array}$ & $\begin{array}{l}\text { Bis-GMA, TEGDMA, Hydrophilic aliphatic } \\
\text { dimethacrylate, Hydrophobic aromatic dimethacrylate, } \\
\text { Silanated barium glass filler, Silanated colloidal silica, } \\
\text { Colloidal silica, dl-Camphor Quinone, Aluminum oxide } \\
\text { filler, Initiators, Accelerators, Pigments. Filler content: } \\
74 \text { wt.\%, } 52 \text { vol.\% }\end{array}$ & $\begin{array}{l}\text { Kuraray } \\
\text { Noritake } \\
\text { Dental, Tainai, } \\
\text { Niigata, Japan }\end{array}$ & B30218 \\
\hline
\end{tabular}

\section{3-2-2. Results.}

Tables 8 present the flexural strength, obtained at two time points. Flexural strength data and their statistical analysis results are given in Tables 8. Except RelyX Unicem 2 Automix, the flexural strength of all core build-up materials changed significantly with time $(p<0.05)$. The one-day time period yielded the highest mean data, except for Clearfil DC Core Automix ONE. For all the three time periods, ESTECORE showed the highest values among all the core build-up materials.

Table 8. Flexural strength of various Core build-up materials and luting materials (MPa, mean (S.D.))

\begin{tabular}{lccc}
\hline & Immediate & After one-day storage & $p$ value $^{\text {a }}$ \\
\hline FluoriCore 2 & $83.3(8.8)$ & $132.0(8.4)$ & $<0.05$ \\
RelyX Ultimate & $71.4(4.6)$ & $119.4(3.6)$ & $<0.05$ \\
RelyX Unicem 2 Automix & $71.9(5.7)$ & $108.0(6.8)$ & $<0.05$ \\
Filtek BulkFill Flowable Restorative & $50.3(1.8)$ & $144.9(5.3)$ & $<0.05$ \\
NX3 & $39.1(5.2)$ & $123.7(9.8)$ & $<0.05$ \\
MultiCore Flow & $99.4(7.4)$ & $142.1(9.1)$ & $<0.05$ \\
UniFil Core EM & $90.8(7.3)$ & $153.6(11.4)$ & $<0.05$ \\
BeautiCore Flow Paste & $112.4(9.3)$ & $140.7(7.9)$ & $<0.05$ \\
i-TFC system Post Resin & $84.3(4.1)$ & $139.4(6.4)$ & $<0.05$ \\
ESTECORE & $122.3(9.1)$ & $172.8(10.2)$ & $<0.05$ \\
Clearfil DC Core Automix ONE & $97.3(19.4)$ & $140.6(9.6)$ & $<0.05$ \\
\hline
\end{tabular}

\section{3-2-3. Discussions.}

Thus the higher value of flexural strength and flexural modulus after 1-day, compared with the immediate condition, resulted partly from the stiffer luting-agents with higher moduli $[4,9,11]$, The improvement in strength and elastic modulus after one day is a result of the improvement in the polymerization rate of cement over time [11].

Flexural strength testing is sensitive to surface defects such as cracks, voids, scratches, and which can influence the fracture characteristics of a brittle material. The degree of high flexural strength is believed to reflect high resistance to surface defects and erosion. Therefore, it is thought that flexural strength is a significant important mechanical property of resin composite materials (luting materials, filling materials and core build-up materials). In the bid to better these materials, ensuing research 
and development efforts should focus on the change of flexural strength with elapsed time [4, 6-8, 22].

In clinical settings, it might be advisable to delay polishing when composite biomaterials are used for luting materials, filling materials and core build-up materials since improved mechanical properties were displayed after 1-day storage. The clinical implication is that dentists and patients must agree to a next-day return visit for polishing to improve the survival rate of their restorations.

It is concluded that the composites used as luting materials, filling materials and core build-up materials were all shown to improve flexural strength and flexural modulus over the course of one day.

\section{References}

1. Irie, M.; Suzuki, K. Current luting cements: marginal gap formation of co, mposite inlay and their mechanical properties, Dent. Mater. 2001, 17, 347-353.

2. Irie, M.; Suzuki, K.; Watts, D.C. Marginal and flexural integrity of three classes of luting cement, with early finishing and water storage, Dent. Mater. 2004, 20, 3-11.

3. Peutzfeldt, A.; Asmussen, E. Determinants of in vitro gap formation of resin composites, J. Dent. 2004, 32, 109-115.

4. Irie, M.; Hatanaka, K.; Suzuki, K., Watts, D.C. Immediate versus water-storage performance of class V flowable composite restoratives, Dent. Mater. 2006, 22, 875-883.

5. Hosaka, K.; Nakajima, M.; Takahashi, M.; Itoh, S.; Ikeda, M.; Tagami, J.; Pashley, D.H. Relationship between mechanical properties of one-step self-etch adhesives and water sorption, Dent. Mater. 2010, 26, 360-367. http://dx.doi.org/10.1016/j.dental.2009.12.007

6. Asmussen, E.; Peutzfeldt, A. Influence of UEDMA, BisGMA and TEGDMA on selected mechanical properties of experimental resin composites, Dent. Mater. 1998, 14, :51-56.

7. Irie, M.; Maruo, Y.; Nishigawa, G.; Suzuki, K.; Watts, D.C. Physical properties of dual-cured luting-agents correlated to early no interfacial-gap incidence with composite inlay restorations, Dent. Mater. 2010, 26, 608-615. http://dx.doi.org/10.1016/j.dental.2010.02.012

8. Takahashi, H.; Finger, W.J.; Utterodt, A.; Komatsu, M.; Woestmann, B.; Balkenhol, M. Factors influencing marginal cavity adaptation of nanofiller containing resin composite restorations, Dent. Mater. 2010, ;26, 1166-1175. http://dx.doi.org/10.1016/j.dental.2010.08.189

9. Irie, M.; Maruo, Y.; Nishigawa, G. Performance of Class I composite restorations when polished immediately or after one-day water storage, PLOS ONE, 2017, 12:e0183381. https://doi.org/10.1371/journal.pone.0183381

10. Irie, M. Shear bond strength to human tooth and flexural strength of current resin cements, J. Jpn. Assoc. Dent. Traumatol. 2007, 3, 9-14.

11. Irie, M.; Maruo. Y.; Nishigawa, G.; Yoshihara, K.; Matsumoto, T. Flexural strength of resin core build-up materials: correlation to root dentin bond strength and pull-out force, Polymers, 2020, 12, 2947; doi:10.3390/polym12122947

12. Gordan, V.V.; Vargas, M.A.; Cobb, D.S.; Denehy, G.E. Evaluation of acidic primers in microleakage of Class 5 composite resin restorations. Oper Dent. 1998;23(5):244-49.

13. Van Meerbeek, B.; Vargas, M.; Inoue, S.; Yoshida, Y.; Peumans, M.; Lambrechts, P. et al. Adhesives and cements to promote preservation dentistry. Oper Dent. 2001; Supplement 6: 119-44.

14. Tay, F.R.; Pashley, D.H. Aggressiveness of contemporary self-etching systems. I: Depth of penetration beyond dentin smear layers. Dent Mater. 2001;17(4):296-308.

15. Feraccane, J.L.; Mitchem, J.C. Relationship between composite contraction stress and leakage in Class V cavities. Am J Dent. 2003;16(4):239-43.

16. Calheiros, F.C.; Sadek, F.T.; Braga, R.R.; Cardoso, P.E. Polymerization contraction stress of low-shrinkage composites and its correlation with microleakage in Class V restorations. J Dent. 2004;32(5):407-12.

17. Irie, M.; Suzuki, K.; Watts, D.C. Marginal gap formation of light-activated restorative materials: effect of immediate setting shrinkage and bond strength. Dent Mater. 2002;18(3):203-10.

18. Bakhsh, T.A.; Sadr, A.; Shimada, Y.; Mandurah, M.M.; Hariri, I.; Alsayed, E.Z.; Tagami, J.; Sumi, Y. Concurrent evaluation of composite internal adaptation and bond strength in a class-I cavity. J Dent. 2013;41(1):60-70. http://dx.doi.org/10.1016/j.jdent.2012.10.003 
19. Mishra, L.; Khan, A.S.; Velo, M.M.A.C.; Saurav, P.S.; Zavattini, A.; Rizzante, F.A.P.; Vega, H.I.A.; Sauro, S.; Monika, L.-S.M. Effects of Surface Treatments of Glass Fiber-Reinforced Post on Bond Strength to Root Dentine: A Systematic Review, MATERIALS; 2020; 13; 8, doi:10.3390/ma13081967

20. Alshali, R.Z.; Salim, N.A.; Satterthwaite, J.D.; Silikas, N. Long-term sorption and solubility of bulk-fill and conventional resin-composites in water and artificial saliva. J. Dent. 2015; 43, 1511-1518.

21. Sokolowski, K., Agata Szczesio-Wlodarczyk, A.; Bociong, K.; Krasowski, M.; Fronczek-Wojciechowska,M.; Domarecka, M.; Sokolowski, J.; Lukomska-Szymanska M. Contraction and Hydroscopic Expansion Stress of Dental Ion-Releasing Polymeric Materials. POLYMERS. 2018; 10;10: doi: 10.3390/polym10101093

22. Peutzfeldt, A.; Asmussen, E. Determinants of in vitro gap formation of resin composites, J. Dent. 2004, 32, 109-115. 